\title{
AUTORIA FEMININA E PARCERIA TEXTUAL: O MONÓLOGO INTERIOR EM MARGUERITE YOURCENAR, LYGIA FAGUNDES TELLES E KATHERINE MANSFIELD
}

\author{
SILVEIRA, Suzane Moraes da Veiga ${ }^{1}$
}

RESUMO: O presente trabalho apresenta um estudo comparativo de três contos de autoria feminina, tendo como base de análise a utilização do monólogo interior como recurso estilístico e procedimento de construção textual. As narrativas investigadas são: "A Primeira Noite" (2011) da escritora belgafrancesa, naturalizada americana, Marguerite Yourcenar; "A Chave" (1970) da brasileira Lygia Fagundes Telles; e "Psicologia" (1992) da neozelandesa Katherine Mansfield. Desse modo, objetiva-se investigar as parcerias textuais que as obras dessas três escritoras empreendem tanto na forma quanto na temática, através da abordagem de questões de gênero e de poder nas relações amorosas.

PALAVRAS-CHAVE: Autoria feminina, parceria textual, monólogo interior.

\section{FEMININE AUTHORSHIP AND TEXTUAL PARTNERSHIP: THE INTERIOR MONOLOGUE IN MARGUERITE YOURCENAR, LYGIA FAGUNDES TELLES AND KATHERINE MANSFIELD}

\begin{abstract}
This paper presentes a comparative study of three short stories written by female writers, having as its element of analysis the use of the interior monologue as a stylistic resource. The texts are: "A Primeira Noite" ("The First Night”) (2011) by the French-Belgium, naturalized U.S. citizen, author Marguerite Yourcenar; "A Chave" ("The Key") (1970) by the Brazilian Lygia Fagundes Telles; e "Psicologia" (Psychology) (1992) by the New Zealander Katherine Mansfield; which have in common the questioning of the difficulty of communication and the (im)possibility of loving relationships.
\end{abstract}

KEYWORDS: Feminine authorship, textual partnership, interior monologue.

\footnotetext{
${ }^{1}$ Doutoranda em Literatura Brasileira pelo programa de pós-graduação em Letras Vernáculas da Universidade Federal do Rio de Janeiro (UFRJ). Contato: suzanemveiga @ yahoo.com.br
} 


\title{
INTRODUÇÃO
}

\author{
Disse a si mesmo, como dissera com frequência, \\ e muitas vezes junto a outras mulheres, \\ que os momentos da vida seriam em sua maioria deliciosos \\ se o futuro ou o passado não projetassem neles as suas sombras, \\ e que de ordinário nós somos infelizes apenas por lembrança \\ ou por antecipação. \\ (YOURCENAR, 2011, p. 22)
}

Podemos notar nos escritos de diversos autores uma espécie de interação profícua e criativa no campo da temática e/ou da forma; um tipo de conjunção de linguagem a partir de relações repetidas nas conexões de escrita e intermédios de procedimentos compositivos que se entrecruzam, resultando, via de regra, em intertextualidades e parcerias textuais. Essas convergências frequentemente vão muito além da mera influência direta entre esses autores, pois ultrapassam fronteiras nacionais e linguísticas aproximando textos de diferentes épocas e lugares. Logo, o literário enquanto categoria de estudo nos direciona a pensar nas figurações de um interlúdio estético entre escritores que aparentemente não estariam conectados. É sobre esse direcionamento que se debruça o presente trabalho em que, através da investigação sobre o monólogo interior, são analisados três contos de autoria feminina: “A Primeira Noite" $(2011)^{2}$ da escritora belga-francesa, naturalizada americana, Marguerite Yourcenar; “A Chave” (1970) ${ }^{3}$ da brasileira Lygia Fagundes Telles; e "Psicologia" (1992) ${ }^{4}$ da neozelandesa Katherine Mansfield.

Entendendo-se parceria textual enquanto processo de relações intertextuais, interculturais e interdiscursivas - no qual é desenvolvido "o estudo dos recursos estéticos entre escritos e o deslocamento de ideias entre autores" (COUTINHO e MUCCI, 2009, p. 09) - é através da intertextualidade que podemos traçar a tessitura dos textos em questão e, assim, delimitar os pontos em que eles se cruzam. Procuramos, pois, identificar nos textos literários as suas proximidades e simetrias, procurando evidenciar o fato de que eles se apresentam como um espaço interdiscursivo, em profunda relação com diferentes códigos constituídos pelo

\footnotetext{
${ }^{2}$ Conto presente no livro Conto azul e outros contos, publicado pela primeira vez no Brasil, em 2011, pela Editora Fronteira. Sua versão original em francês, Le premier soir, em Conte bleu, foi publicada, postumamente, em 1993. ${ }^{3}$ Conto presente no livro Antes do baile verde, publicado originalmente pela Editora Bloch em 1970.

${ }^{4}$ Conto presente no livro Felicidade e outras estórias publicado pela primeira vez no Brasil em 1992 pela Editora Revan. Publicado originalmente em 1920, como "Psychology", constante no livro Bliss and other stories.
} 
diálogo entre textos e leituras. Por esse motivo, para a pesquisadora e ensaísta Tânia Carvalhal em O próprio e o alheio: ensaios de literatura comparada (2003), a intertextualidade pode ser compreendida como um dado da percepção textual (p. 76).

Dessa forma, é possível promover confluências entre os textos citados à luz das relações intertextuais e interdiscursivas que eles promovem, especialmente em relação às escolhas estéticas das autoras na escrita dos contos, notadamente o monólogo interior, que se desdobra em fluxo de consciência e discurso indireto-livre.

\section{O monólogo interior, o fluxo de consciência e o discurso indireto-livre}

O monólogo interior é um conceito literário que, segundo Carlos Reis e Ana Cristina Lopes em Dicionário de Narratologia (1996), expressa o surgimento de pensamentos e sentimentos das pessoas fictícias de um livro, remetendo a uma técnica narrativa que viabiliza a representação da corrente de consciência de uma personagem: "o monólogo interior encena uma narração executada sobre a irrupção espontânea de reflexões, cujo teor desordenado e caótico é devido justamente ao imediatismo de tal narração" (p. 60, grifos dos autores). Ele está concentrado no eixo próprio de interseção entre literatura e psicanálise, sendo ferramenta principal da escrita em discurso indireto-livre, a qual foi largamente desenvolvida pelos romancistas modernos do século XX. Podemos citar vários nomes importantes de escritores que fizeram uso dessa forma de escrita como recurso estilístico: James Joyce, Virginia Woolf, Clarice Lispector, dentre outros autores, a fim de evidenciarem o discurso de suas personagens, sem a forte presença do narrador.

Em relação ao discurso indireto-livre, em Ensaios machadianos, Mattoso Câmara Jr. conceitua-o como o recurso que "estabelece um elo psíquico entre o narrador e o personagem que fala" (CÂMARA JR., 1977, p. 30). Segundo o autor, é no discurso indireto-livre que ocorre uma aproximação entre narrador e personagem, dando origem a uma espécie de comunicação unívoca. Ressalta ainda que esse tipo de citação exige muito do leitor, pois a fala da personagem não é ressaltada por aspas, nem introduzida por verbo dicendi (aquele que indica a ação da personagem ex.: disse ela, pensou ele) ou travessão. A fala surge de repente, no meio da narração, como se fossem palavras sem narrador, mas na verdade são as palavras da personagem (Idem). Paralelamente, Othon Garcia em Comunicação em prosa moderna, ao afirmar que o discurso indireto-livre "é uma técnica narrativa muito fértil em recursos estilísticos", destaca o fluxo de consciência e o monólogo interior como seus "recursos-chave": 
[É no monólogo interior] que o narrador (...) apresenta as reações íntimas de determinada personagem como se as surpreendesse in natura, como se elas brotassem diretamente da consciência, livres e espontâneas. O autor "larga" a personagem, deixa-a entregue a si mesma, às suas divagações, em monólogo com seus botões, esquecida da presença do leitor ou ouvinte. Daí o seu feitio incoerente, incoerência que pode refletir-se tanto numa ruptura dos enlaces sintéticos tradicionais quanto numa associação livre de ideias aparentemente desconexas. O autor tenta assim traduzir o "fluxo de consciência", que Robert Humphrey estuda em Stream of consciousness in the modern novel (2002, p. 139)

Como podemos verificar na passagem acima, no monólogo interior, a personagem entra em contato consigo mesma, expressando seus devaneios e sentimentos como se falasse ao espelho, remetendo à metáfora utilizada por Othon Garcia: "trata-se de uma frase que muito nos lembra 'depoimento' feito em divã de psicanalista” (2000, p. 138). Do mesmo modo, Marina Schirato em seu ensaio "O papel do monólogo interior na construção da personagem no conto "Felicidade" de Virginia Woolf" (2010) afirma que o monólogo interior é o momento do discurso da personagem, no qual se depara com aquilo que ocorre em sua mente, "acessando as informações e sensações mais profundas, seguindo o que Freud denominou como associação livre, processo indispensável à técnica do 'talking cure', conhecida também como 'cura pela fala", (p. 07).

Já o fluxo de consciência seria, conforme indica Schirato, a forma "desenfreada" de expressar esses sentimentos: os fatos são narrados torrencialmente, no intuito de fazer a personagem expor-se em seus relatos, abrindo-se mão até mesmo de recursos gramaticais (pontuação, paragrafação, etc.) em favor da fluidez do relato de sua personagem (SCHIRATO, 2010, p. 08). Ainda segundo a autora, o monólogo interior e o fluxo de consciência serviriam para revelar ao leitor os processos de construção da personagem, sua interação com outras vozes do texto e o modo como ela enxerga a si mesma e ao outro, mostrando aspectos da "tomada de consciência" dos elementos de sua vida os quais eram antes estranhos a ela: "Tratase da revelação de algo que, a princípio, subjaz à consciência da personagem, mas ainda não está manifesto. É a expressão daquilo que está submerso (recalcado no inconsciente, como diria Freud) e do difícil percurso para se chegar à superfície” (Idem, p. 10). 


\section{Devaneio da desilusão: o monólogo interior e as projeções da memória}

No conto "A Primeira Noite" de Marguerite Yourcenar entramos em contato com os pensamentos de Georges, a personagem principal do conto, que procura remontar sua vida em passado, presente e futuro, através de um intenso monólogo interior, tentando, assim, dar ordem à difusa projeção de lembranças e expectativas de seu fluxo de consciência. $\mathrm{O}$ devaneio tem papel fundamental na construção dessas reminiscências que interligam diferentes lugares e episódios temporais, com um sentido de autoconhecimento para aquele que divaga e a impressão de que, segundo aponta Gaston Bachelard (1996), "um mundo se forma no nosso devaneio, um mundo que é o nosso mundo. E esse mundo sonhado ensina-nos possibilidades de engrandecimento de nosso ser nesse universo que é nosso. Existe um futurismo em todo universo sonhado" (p. 08). Assim, entre prazeres e desilusões, o homem procura atribuir algum sentido às frustrações e alegrias que o levaram até o momento em que o conto se inicia, casado e partindo para a sua primeira noite de núpcias, bem como, dentro de seu mundo particular, ensaiar futuros possíveis para si e para sua recém-noiva.

Era uma viagem de núpcias. O trem seguia para a Suíça trivial: sentados no compartimento reservado, eles davam-se as mãos. (...) Ele mais experiente, sentindo toda a fragilidade do sentimento que o impelira para essa moça, destinada a tornar-se banal quando se tornasse mulher. O que nela lhe agradara era precisamente o que iria desaparecer, a candura, os espantos, a atmosfera de intacta juventude em que a conhecera. (YOURCENAR, 2011, p. 19)

Com um olhar cínico sobre o amor, Georges vislumbra um futuro decadente para a sua jovem esposa, Jeanne, ao mesmo tempo em que se lembra de suas experiências amorosas passadas com outras mulheres e pensa sobre o modo como uma mulher deve ou não se comportar. Ele traça para si e para a sua cônjuge toda a sorte de infortúnios e desventuras de uma vida de casados, a qual vê com profunda melancolia e desprezo, pois considera o casamento uma espécie de "prisão aveludada" que, com o passar do tempo, o faria perder a liberdade que tivera em juventude. Quanto a Jeanne, Georges pinta em pensamento, igualmente ou pior, um triste futuro de esposa e dona-de-casa destinada à monotonia do lar e ao enfado da vida conjugal. 
Como se o trem atravessasse as paisagens do futuro, ele viu a longa série dos dias monótonos em que a chegada de uma amiga seria para ela uma diversão, as noites em que se alegraria de ir ao encontro do círculo de homens que falariam de outras mulheres com uma brutalidade que lhe daria prazer, (...) Teria ela um filho? Naturalmente. Tentou imaginá-la grávida. Então ele lhe daria um filho que ela se felicitaria por gerar, embora a enfeasse e lhe desse enjôos. (Ibid., p. 20)

Assim, Georges revela em seu monólogo interior toda a hipocrisia que ronda os preceitos ditos pela sociedade, como casamento, filhos, trabalho; questionando-os em tom sarcástico. Amargo, teme, portanto, amalgamar-se aos padrões que, para ele, começariam com o casamento, e fariam com que ele perdesse o que tem de mais precioso que é sua individualidade, seria enfim "como todo mundo": "Ou, quem sabe, ele se deixaria atingir docemente pela cegueira conjugal e paterna que havia criticado nos outros, vencido (somos sempre vencidos) pela vida que tende a fundir todos os seres em moldes idênticos?" (YOURCENAR, 2011, p. 21). Apresenta, dessa maneira, uma visão desiludida da vida, quando muito pessimista, concebendo valores como fidelidade e bem-estar familiar como inócuos e pueris. A alegria aparece como falaciosa e a felicidade como uma mentira contada sucessivas vezes e tida como verdade. Com um ar sádico e irônico, imagina a face grotesca que se mostrará no cotidiano para sua jovem noiva, a qual ele crê ingênua e insensata, como uma sucessão de decepções e frustrações.

Seria ela de fato tão simples que esperasse da vida a revelação de um segredo, quando a vida só nos traz incessantes lenga-lengas? Acabaria por implorar de um amante a felicidade que ele não lhe houvesse dado, que um outro também não a daria, porque não a teria para dar? Chegaria a supor que alguém possui a felicidade na carteira, como um cheque que bastasse endossar? Existem cheques sem fundos. Sentiu vontade de rir à ideia de que amanhã ela iria acusá-lo de vigarista. (Ibid., p. 20)

As imagens que Georges projeta sobre o seu futuro e o da jovem mulher aparecem como flashs que vão se consolidando e ganhando formas como quadros na cabeça do recém- 
esposo, os quais se assemelham com a própria paisagem da viagem do trem, como diria Bachelard (1996, p. 08): “A imaginação tenta um futuro. A princípio ela é um fator de imprudência que nos afasta das pesadas estabilidades”. Dessa forma, durante o conto, na viagem que os noivos fazem até o Grand-Hotel para a sua noite de núpcias, duas paisagens são apresentadas: aquela exterior que eles vislumbram através das janelas do trem e uma paisagem interior feita de outras matizes: de memórias e desejos que se misturam e combinam. No frenesi de seu fluxo de consciência, Georges chega mesmo a confundir passado e presente, ao lembrarse de sua amante Laurie, da qual ele se desvencilhara para realizar seu casamento com Jeanne. Georges a descreve sempre de forma melancólica como se tivesse remorsos por tê-la deixado, ao mesmo tempo em que sente um grande alívio por não ter mais uma espécie de compromisso com essa mulher a quem ele amara e desprezara ao mesmo tempo.

Podemos perceber no conto que Laurie, a meretriz, representa, na cabeça de Georges, o seu passado de vida mundana e de viagens como rapaz inconsequente e imaturo; e Jeanne, seu futuro monótono e hipócrita como homem sério e casado. Com Laurie, Georges revive, em memória, momentos de prazer que tiveram juntos, com grave sensação de angústia e enfado. Para ele, ela não fora senão uma diversão a qual ele consumira por inteiro. Vaidoso, Georges imagina o sofrimento que causara à mulher contemplando-se como um vencedor em relação ao seu passado.

A retrospectiva evocou nele a imagem de uma outra mulher, a sua amante, com a qual havia rompido, e de quem espantava-se por ainda lembrar. Estaria ela chorando? Prendendo as lágrimas? (...) Tinham vivido juntos vários anos: ele se voltava para a época daquele amor com uma indulgência que provinha de uma amnésia parcial, e a certeza de que aqueles dias não voltariam deixouo menos severo em relação ao grau de felicidade que lhe haviam dado. Com ela visitara a Itália e a Provença; episódios dessa viagem, a qual o entediara, comoviam-no às lágrimas, e a lembrança daquelas paisagens radiosas fê-lo detestar, por um segundo, as que lhe surgiam aos olhos. Depois viera a familiaridade; por fim, a lassidão; o prazer de romper era o único que ele ainda podia extrair dela; vira-a chorar, no dia em que lhe anunciara seu casamento, e experimentara certa vaidade de ser por ela amado o suficiente para fazê-la sofrer. (YOURCENAR, 2011, p. 24) 
Do mesmo modo, no conto "A Chave" de Lygia Fagundes Telles, temos uma situação bem parecida com “A Primeira Noite”, pois Tomás, a personagem principal da estória e também o narrador, durante um devaneio, relembra fatos de sua vida passada ao lado de Francisca, sua antiga esposa, a quem abandonara para ficar ao lado de Magô. Egoísta, assim como Georges, não hesita em agir segundo seus próprios interesses mesmo que, para isso, tenha de se desvencilhar de uma pessoa querida. Alguns dos temas principais abordados no conto de Telles se referem ao processo de envelhecimento e ao próprio tempo como fator de amadurecimento pessoal, tendo como pano de fundo, assim como no conto de Yourcenar, a hipocrisia que ronda os relacionamentos amorosos das personagens masculinas principais, baseados em conveniência e interesse.

Tomás, um homem prestes a completar seus cinquenta anos, desde o início da narrativa mostra-se extremamente incomodado com Francisca, sua esposa, pela parcimônia com que ela, na sua visão, aceitara a velhice. Para ele, os dois ainda tinham muito para viver e ele exigia dela o posicionamento e a energia de uma mulher mais jovem. Queria, assim, que ela se vestisse de forma mais extrovertida, se maquiasse e saísse mais: "Deu-lhe um vidro de perfume. Deu-lhe um batom (...) Deu-lhe um colar de contas vermelhas (...) 'somos jovens ainda, minha querida! Vamos reagir?"” (TELLES, 1982, p. 51). Tomás não consegue compreender o porquê de Francisca não se torturar diante do envelhecimento, processo que, para ele, representava sofrimento e angústia. Ao conhecer Magô, uma mulher de dezoito anos, Georges sente-se um novo homem, como se todo o furor de juventude da moça o fizesse recobrar a sua própria, a qual acreditava perdida.

Aquela obsessão de idade. Por que falava tanto em idade? Chegava a ser irritante às vezes. 'Também tenho cinquenta anos como você, não tenho? Por acaso vou agora cobrir a cabeça e esperar a morte?'. Ela colocara o disco na vitrola. 'Tomás, você já viu como a noite está bonita? Por que não vai dar uma volta? Ele foi. Na volta, encontrara Magô. Teve a sensação de nascer de novo quando ela o chamou de Tom. Sentira-se um novo homem. Outro homem" (Ibid., p. 46)

Francisca é descrita pela memória de Tomás como uma mulher doce, meiga e extremamente calma que teria se conformado em aceitar a velhice sem revolta e que até se sentia bem com isso. É por vezes identificada no conto, através do fluxo de consciência de 
Tomás, como aquela que gosta de relembrar o passado, escutar músicas antigas e reviver bons momentos, sem pensar muito no futuro. Interessante notar que, na cabeça do narradorpersonagem, Francisca é caracterizada como aquela capaz de tudo perdoar, tolerante e altiva, como uma amiga ou uma mãe.

Assim como no conto "A Primeira Noite", em "A Chave", há uma assimetria de idades, de poder e de interesses entre as personagens masculinas e as femininas, sendo importante ressaltar o fato de que apenas temos conhecimento sobre Jeanne, Laurie, Francisca e Magô pelos olhos de Georges e Tomás. No primeiro conto, Tomás e Laurie, que funciona como uma espécie de iniciadora amorosa (e sexual) para o rapaz, possuem uma grande diferença de idade: ela madura e vivida, ele ainda um jovem rapaz quando a conheceu, inexperiente e ávido por novas experiências. Georges estabelece um paralelo em seus pensamentos entre Laurie e Jeanne, a primeira como seu passado, de quem de certa forma, foi um aprendiz e se submeteu como inexperiente; e a segunda como seu futuro, a quem pretende dominar em inteligência e vivência.

No segundo conto, a relação assimétrica de poder também fica nítida quando Tomás deixa a esposa por uma mulher bem mais jovem, a qual o homem tem a intenção de controlar por completo seja por ser muito mais experiência, seja pelo dinheiro. Ele pede a permissão do pai da menina para iniciar o relacionamento, o qual o adverte sobre a diferença de idade, Tomás, porém, ignora o aviso e segue com a jovem: “O caso é que minha filha tem só dezoito anos e o senhor tem quarenta e nove, a diferença é muito grande! (...) Hoje não soma tanto. Mas daqui a dez anos como vai ser?” (TELLES, 1982, p. 49). A narrativa avança os dez anos e temos a caracterização de Magô em seus vinte e oito anos, a qual tornou-se uma mulher repleta de caprichos e desejos - para o desespero de Tomás, que agora sente o peso da diferença de idade entre os dois. Ele se lembra, então, de Francisca e sofre por não ter aquela calmaria para que possa descansar. O furor de juventude que tanto o atraíra em Magô no passado, agora causa-lhe repulsa, pois a timidez de adolescente dera lugar à desenvoltura e autoafirmação da adulta.

... E como se exprimia bem, a sonsa. Contudo, há alguns anos, que enternecedor vê-la roendo as unhas quando se intimidava. Ou morder o lábio inferior quando não sabia o que dizer. E nunca sabia o que dizer. "Vai desabrochar nas minhas mãos" - pensou, emocionado até às lágrimas. Desabrochara, sem dúvida. Lançou-lhe um olhar. "mas não precisava ter desabrochado tanto assim.” (Ibid., p. 47) 
Em intenso monólogo interior, Tomás a insulta, recorda-se de Francisca e atormentase por não conseguir corresponder ao que ele se refere como "a fúria da juventude", que é o desejo sexual de Magô. Ele pensou que, ao ficar com ela, recuperaria a sua própria juventude, como se pudesse sorvê-la da garota. Agora, Magô tem atitudes de autoritarismo e desprezo em relação a ele, justamente como que ele fizera com Francisca anos antes, exigindo dele que reaja, que se anime. Em devaneios, ele a xinga em pensamento, chama-a de "cretina, "sonsa", "exibicionista". O conto termina, assim, com a sensação de melancolia de Tomás ao se confrontar consigo mesmo:

Baixou o olhar para os próprios pés. E quase chegou a sorrir. Com aquelas meias, pareciam pés de um rapaz, ela gostava das cores fortes. Francisca preferia cores modestas, mas Magô era jovem e os jovens gostam das cores fortes, principalmente os jovens que vivem em companhia de velhos. E que desejam disfarçar esses velhos sob artifícios ingênuos como meias de cores berrantes, camisas esportivas, gravatas alegres, alegria, meus velhinhos, alegria! Dia virá em que ela vai querer que eu pinte o cabelo. (...) Ela adorava espelhos, tinha espelhos por toda a casa. Aquele ali então era o pior, aquele que apanhava o corpo inteiro, sem deixar escapar nada. Com ele aprendera que envelhecer é ficar fora de foco: os traços vão ficando imprecisos e o contorno do rosto acaba por se decompor como um pedaço de pão a se dissolver na água. (Ibid., p. 47-49)

Em "Psicologia", de Katherine Mansfield, todo o diálogo e monólogo interior das duas personagens principais acontece em um ambiente fechado, uma sala de estar, em que "Ele" e "Ela" - sem nome ou sobrenome -, identificados apenas pelo gênero, revelam em pensamento aquilo que gostariam de dizer um ao outro, mas que, por vergonha ou receio, não expressam em palavras. Nesse conto, a autora de Bliss parece querer conjugar conceitos da psicologia e da literatura colocando em questão a aproximação entre as duas disciplinas, aludindo a um tipo de fazer literário que vigorou no início do século XX, notadamente o romance psicológico. Este tipo de escrita pretende realizar uma espécie de incursão ao íntimo do ser humano, em seus domínios mais recônditos e selvagens, como nos lembra Tânia Carvalhal (2003): "muitas vezes, 
o autor tenta recriar nos domínios de sua arte os efeitos ou recursos técnicos de outra forma de expressão com a qual está familiarizado" (p. 41).

Assim, podemos perceber no conto que o narrador atua como um analista sobre os pensamentos de "ela" e "ele", analisando e questionando o posicionamento das personagens, as quais revelam, em diversos momentos, a distância que existe entre intenção e gesto, pensar e dizer, e querer e realizar - o que denota uma falta de coragem das personagens em dar vazão àquilo que estão sentindo. Logo no início do conto, há o encontro físico dos dois e um apelo secreto de cada um deles a uma comunicação não-verbal. O discurso representa um obstáculo para os dois amantes, porque se interpõe ao livre desejo que se encontra cerceado em normas e preceitos:

O eu secreto de cada um deles sussurrava:

"Por que deveríamos falar? Isto não é o bastante?

"Mais do que bastante. Até agora eu não tinha pensado..."

"Como é bom simplesmente estar com você..."

"Como agora"

"É mais do que bastante."

(MANSFIELD, 2010, p. 30)

Os dois temem estragar o momento vivido por eles com palavras que, ao serem pronunciadas, destoassem daquilo que realmente queria ser dito pelo interlocutor. Por isso, a fala é, a todo o momento, alegórica. As frases pronunciadas por "ele" e "ela" sempre remetem para outra fala secreta, impronunciável. O dizer cotidiano é sempre uma interrupção para o essencial que deveria ser dito e que, no entanto, permanece inescrutável. Devido a este fato, a presença dos dois por vezes torna-se solene, o que dificulta a aproximação tão desejada.

Tomar chá ali era um assunto muito agradável: ela oferecia sempre coisas deliciosas para comer - pequenos sanduíches picantes, dedinhos de amêndoas doces e um bolo escuro gostoso, sabendo a rum -, mas isso era uma interrupção. Ele ansiava pelo momento em que terminado o chá, a mesa retirada, as duas cadeiras levadas para perto do fogo, chegasse a hora de pegar o cachimbo, enchê-lo e dizer, comprimindo o tabaco dentro do fornilho: "Estive pensando sobre o que você me disse na última vez que nos encontramos e parece-me que..." Sim, isso era o que ele esperava, e ela também (Ibid., 30). 
Em seus devaneios, a jovem de trinta anos, observa a si mesma e a ele em um quadro mental como se formassem uma pintura muito realista, sonhando com os momentos em que “ele, recostando-se muito à vontade sobre as almofadas e ela, enrodilhada na poltrona azul, em forma de concha, como se fora um escargot" (MANSFIELD, 2010, p.30) aproveitassem a companhia um do outro sem a mediação das palavras. Ao contrário das personagens de "A primeira Noite" e "A Chave", em "Psicologia" nós podemos acessar o pensamento da mulher, que é o outro silencioso dos dois primeiros contos, bem como podemos perceber que a relação entre "ele" e "ela" não é assimétrica. Diferentemente dos pares Georges e Jeanne, e Tomás e Magô ou mesmo Tomás e Francisca; "ele" e "ela" se respeitam e admiram, são duas almas que se amam, mas que não conseguem superar o medo de perderem a amizade que eles comungam pela aventura de uma relação amorosa. Desse modo, "ela" e "ele" parecem estar em posições simétricas de poder, pois os dois parecem compreender as mentes um do outro, estando suas atenções voltadas totalmente para a estética, para uma relação quase abstrata, como se ambos teorizassem sobre a (im)possibilidade de relacionamentos amorosos.

Pois a qualidade especial comovente daquela amizade era a total entrega. Como duas cidades abertas no meio de uma vasta planície, suas mentes abriam-se uma para a outra. E não era como se ele cavalgasse na dela, como um conquistador, armado até os dentes e nada mais vendo senão um alegre ondular de seda; nem ela entrava na mente dele como uma rainha, caminhando docemente sobre pétalas... Não, eles eram viajantes atentos, sérios, absorvidos em compreender o que estava para ser visto e descobrir o que estivesse escondido, tirando o melhor proveito dessa oportunidade extraordinária, absoluta, que possibilitou a ele ser absolutamente verdadeiro com ela e possibilitou a ela ser absolutamente sincera com ele. (p. 31)

A sala de encontro do homem e da mulher figura na imaginação dele como um local mágico, no qual não há vida exterior, um refúgio em que pudessem estar plenamente um com o outro. O homem afirma viver um carpe diem ao lado da mulher, não se lembrando de notícias, lugares, da comida que consome, da aparência das pessoas, exceto do estúdio onde eles se veem. Ali parece ser o lugar especial em que as coisas possuem um significado secreto, como que sussurrando para ele maravilhas. 
Pra mim uma sala é sempre igual a outra sala - um lugar onde nos sentamos para ler ou conversar, exceto - aqui ele parou e sorriu de maneira ingênua e estranha e disse - "exceto esse estúdio." Olhou à volta e depois para ela; riu em sua perplexidade e prazer. (...) "Veja que coisa esquisita: de olhos fechados, posso ver este lugar em cada detalhe - cada detalhe. Estou pensando isso agora; nunca antes havia tomado consciência disso. Muitas vezes, quando estou fora daqui, torno a visitar em espírito este lugar; vagueio por entre suas poltronas vermelhas, admiro a fruteira sobre a mesa preta e apenas toco, muito de leve, aquela maravilha que é a cabeça do menino adormecido.” (p. 32)

Entre muitos silêncios, entretanto, os dois não sabem o que dizer ou o que fazer, parecem em certos momentos como atores a encenarem um diálogo, eles se veem de fora como um projeção de cinema. O excesso de racionalidade opera uma ruptura entre desejo e ação. Eles tentam vencer o silêncio ao passo que fracassam por não conseguirem deixar de se controlarem o tempo todo. Em seus monólogos interiores, eles se culpam por serem tão desconfiados, tão excessivamente teatrais, apesar de estarem os dois muito envolvidos emocional e psiquicamente.

O coração dele batia, o rosto dela ardia, e o absurdo era que ela não podia descobrir onde exatamente eles estavam e o que exatamente estava acontecendo. (...) Bem, por que eles simplesmente não deixavam as coisas correrem, não se entregavam, para ver o que ia acontecer depois? Mas não. (...) Sobre o que estiveram conversando?" pensou ela. E o viu penosamente sim, penosamente - preparando o solo, ela correndo atrás, colocando aqui uma árvore, ali um arbusto florido, lá um punhado de peixes brilhantes num lago. Desta vez, estavam silenciosos por puro desalento. O relógio bateu seis pequenos silvos alegres, e o fogo agitou-se brandamente. Que tolos eles eram - pesados, enfadonhos, envelhecidos, com cabeças positivamente entulhadas. (Ibid., p. 35)

Ao final do conto, os dois fracassam por não conseguirem se entregar, por não assumirem o sentimento que eles sentem um pelo outro. Eles se ferem pelas palavras que não foram ditas e que doem como navalhas na carne: "Você me feriu, você me feriu. Nós 
fracassamos!" disse o eu secreto dele (...) "Você me feriu, você me feriu" - dizia o coração dela. "Por que você não vai? Não, não vá. Fique. Não, vá" (MANSFIELD, 2010, p. 35-36).

\section{CONSIDERAÇÕES FINAIS}

Conforme aponta Tânia Carvalhal (2003), todo estudo de literatura comparada teria por finalidade a descrição de uma passagem, como uma espécie de transporte entre textos de "alguma coisa literária" (CARVALHAL, 2003, p. 15) para além de uma fronteira linguística. Assim, através da análise dos três contos, podemos pensar a intertextualidade como um processo de interação intercultural e intersemiótica, vislumbrando parcerias textuais inusitadas e bem-sucedidas. Nelas, há o transbordamento da utilização do que veio a se configurar como um recurso estético e estrutural presente nesses textos, que é o monólogo interior, e um dos modos como ele se apresenta, o fluxo de consciência, abordados no presente trabalho.

Além disso, há a presença, nos três contos de autoria feminina, da abordagem da relação assimétrica entre as personagens masculinas e femininas, a tematização da incomunicabilidade nos relacionamentos amorosos e a forma como as personagens são influenciadas pelo tempo. As projeções da memória que conduzem as personagens a diversos momentos temporais e espaciais funcionam como articulação da narrativa, e o devaneio como o estado de transe e ebriedade que possibilita o estado mental do fluxo de consciência, como se os pensamentos e as lembranças das personagens em monólogo interior compusessem cenas de um filme aos olhos do leitor, em sonhos acordados. Essa fluidez da narrativa aliada a uma escrita voltada às questões que afligem o ser humano em suas fraquezas e incertezas são uma constante nos contos analisados em que temas como o amor, os padrões sociais, a velhice e o medo são elementos norteadores da leitura, conferindo às obras analisadas um diálogo textual, cultural e discursivo.

\section{REFERÊNCIAS BIBLIOGRÁFICAS}

BACHELARD, Gaston. A imensidão íntima. In: A poética do espaço. Trad. Antônio de Pádua Danesi. São Paulo: Martins Fontes, 1986.

. A Poética do Devaneio. Tradução Antônio de Pádua Danesi. São Paulo: Martins Fontes, 1996. 
CÂMARA JR., J. Mattoso. Ensaios machadianos. 2. ed. Rio de Janeiro: Ao livro técnico, 1977. CARVALHAL, Tânia Franco. O próprio e o alheio: ensaios de literatura comparada. Rio Grande do Sul: Editora Unisinos, 2003.

COUTINHO, Luiz Edmundo; MUCCI, Latuf Isaias (Organizadores). Fulgurações: parcerias textuais e o decadentismo (ensaios críticos). Rio de Janeiro: Confraria do Vento, 2009.

GARCIA, Othon M. Comunicação em prosa moderna: aprenda a escrever, aprendendo a pensar. $19^{\mathrm{a}}$ ed. Rio de Janeiro: FGV, 2000.

MANSFIELD, Katherine. Psicologia. In: Felicidade e outros contos. Nova Fronteira, 2010.

REIS, Carlos; LOPES, Ana Cristina M. Dicionário de narratologia. 5 ed. Coimbra: Livraria Almedina, 1996.

SCHIRATO, Marina Nobre de Moraes. O papel do monólogo interior na construção da personagem no conto "Felicidade" de Virgínia Woolf. Artigo publicado na revista eletrônica da Universidade Presbiteriana Mackenzie publicado em 2010. Disponível em: http://www.mackenzie.br/fileadmin/Pos_Graduacao/Mestrado/Letras/Volume_10/Artigo_Mar ina.pdf. Acesso dia 20 dez. 2011 às 10:00.

TELLES, Lygia Fagundes. Antes do Baile Verde. São Paulo: Ática, 1982.

YOURCENAR, Marguerite. Conto azul e outros contos. Tradução de Joana Angélica D'Ávila Melo. 2 ed. Rio de Janeiro: Nova Fronteira, 2011. 